\title{
Homeostaticity of energy systems: How to engineer grid flexibility and why should electric utilities care
}

\author{
Fernando Yanine ${ }^{1}$, Antonio Sanchez-Squella ${ }^{2}$, Aldo Barrueto ${ }^{2}$, Sarat Kumar Sahoo ${ }^{3}$, Antonio Parejo ${ }^{4}$, Dhruv \\ Shah $^{5}$, Felisa Cordova ${ }^{1}$ \\ ${ }^{1}$ Universidad Finis Terrae, Faculty of Engineering; Santiago, Chile. fyanine@uft.cl; fcordova@uft.cl \\ ${ }^{2}$ Universidad Tecnica Federico Santa Maria (UTFSM), Department of Electrical Engineering \\ Santiago, Chile. antonio.sanchez@usm.cl; aldo.barrueto@usm.cl \\ ${ }^{3}$ A Constituent College of Biju Patnaik Technological University, Parala Maharaja Engineering College, Department of Electrical \\ Engineering, Govt. of Odisha, Sitalapalli, Berhampur PIN-761003 Odisha State INDIA. sarata1@ rediffmail.com \\ ${ }^{4}$ U. de Sevilla, Escuela Politecnica Superior, Dept. of Electronic Technology; C/ Virgen de Africa 7, Seville, Spain. aparejo@us.es \\ ${ }^{5}$ Mukesh Patel School of Technology Management \& Engineering (MPSTME); MUMBAI CAMPUS, India. dhruv.shah@nmims.edu
}

\section{Article Info}

Received Dec 17, 2018

\section{Keyword:}

Energy homeostaticity

Sustainable energy systems

Environmental challenges

Proactive response

Reactive and predictive homeostasis

\begin{abstract}
Today's power generation and distribution industry is being faced with a number of issues, from violent weather phenomena to earthquakes, fires and landslides; including acts of arson, terrorism and vandalism, all of which pose serious concerns for the sustainability of the distribution and supply of electricity. Electric utilities like ENEL are cognizant of this fact and know they must take action. Moreover, they are required by law to be prepared and act proactively to prevent service disruption, by responding to such challenges rapidly and effectively so as to preserve stability and continuity of operation. Homeostaticity of energy systems seeks just that: to bring about a rapid, effective and efficient state of equilibrium between energy supply and expenditure at all times, whatever the circumstances, to preserve stability of systems operation. The paper presents a prescriptive energy homeostaticity model being considered by ENEL as a means to further the incorporation of renewables in the electricity generation and distribution industry. The aim is to enhance control and energy management systems in distributed generation installations tied to the grid for urban and rural communities, in order to complement and diversify their electric power distribution services. The theoretical groundwork underlying the subject as well as other relevant contextual factors are also discussed and simulation results are presented under different tariff scenarios, and energy storage alternatives, in order to compare the proposed model with the actual case. Energy storage (ES) is found to be of paramount importance in the overall analysis of the results as it enhances and reinforces thriftiness on energy consumption.
\end{abstract}

\section{Corresponding Author:}

Antonio Sanchez-Squella, Departement of Electrical Engineering, Universidad Tecnica Federico Santa Maria, Avda. Vicuña Mackenna 3939, San Joaquín, Santiago, Chile · +56 $223037000 \cdot+56223037001$.

Email: antonio.sanchez@usm.cl 


\section{Introduction}

In today's world, electric utility services are facing a number of threats, from harsh, and unexpected weather events like torrential rains, winds or heavy snow in regions that did not normally have these happenings, as well as natural disasters like earthquakes and large fires, right along with unexpected malicious acts. The issue has hit the United States of America quite hard in later years and measures have been taken about these threats. In 2014 the US Senate passed a bill supporting grid-connected distributed energy systems like microgrids to confront the growing climate threats, so as to make electric power distribution more resilient and proactive towards the unexpected, particularly harsh weather like storms and floods. This is in line with Smart Grid transformation and modernization in the US, Canada and Europe. Such initiatives being led by big players like ENEL, have spurred several pieces of legislation not only in North America but also in South America, where changes in the electric law are being studied by industry stakeholders, legislators, and also by several local and federal authorities to promote a range of technologies and policies that can make the grid more reliable, resilient and cyber-secure [Web-1, Web-2]. All of these steps fall, in one way or another, on the path set forth by President Obama in 2013, when he introduced the Energy Independence Roadmap for the country [Web-2]. However, the pace towards more decisive and concrete steps to bring about badly needed industry changes have somehow sped up even more, following the catastrophic natural disasters that the US has had to endure in recent years (Blake and John, 2013). Among such initiatives are grants, microgrid technologies' demonstration projects, university initiatives, and various studies to determine the costs involved in the industry transformation and to define the precise scope of action in order to shape federal microgrid policy in the immediate future (Oceanic and Service, 2013). A significant step forward was the Energy Policy Modernization Act of 2015, that was introduced in the US Senate on September 2015, marking it a significant step forward towards Grid modernization in the US.

In Chile, like in North America, authorities are very concerned at the gloomy outlook of having public utility services shutdown and transport infrastructure break down and collapse as a result of earthquakes and violent weather phenomena. Both types of phenomena are nothing new in Chile and are expected to become more severe in years to come (Becena and Zagal, 2012). In this context, some power and water utilities are already taking action by adopting plans to counteract or fend-off such adverse conditions and circumstances, like those that prompt wild fires. One of such utilities is ENEL Distribucion in Chile, which currently supports ongoing research on Smart Grid transformation to explore the potential incorporation of grid-tied microgrids in the already huge number of buildings in the city of Santiago. The city is Chile's capital and has a very large metropolitan area being serviced by ENEL, as a complementary alternative to grid-only power distribution. Hence the present paper discusses such research initiative by first presenting a prescriptive energy and power management control system model (EPMCSM) which employs energy homeostaticity (EH) by means of homeostatic control (HC) strategies for microgrids (Yanine and Rother, 2017; Yanine and Sahoo, 2017). The model is being considered by electric utilities like ENEL in Chile to operate grid-tied microgrids of different sizes that have the potential of being installed and operated by utilities like ENEL in the large stock of residential and commercial buildings, Enel Distribucion is part of ENEL Chile (https://www.enelchile.cl/es.html.html), the largest electric utility in Chile and in the region.

The work presented here is part of an ongoing research program funded by CONICYT (Comisión Nacional de Investigación Científica y Tecnológica) of Chile under the auspice and support of ENEL Distribucion. Section 2 explains how homeostaticity of energy systems can be incorporated to electric power systems and its advantages. Section 3 briefly shows the control engineering design, simulations and results. Finally, section 4 presents the conclusions.

\section{How to incorporate energy homeostaticity in electric power systems?}

Ever since Cannon first formulated the concept of homeostasis over 80 years ago (Cannon, 1929, 1935), attention has largely been focused on corrective responses initiated after the steady state of the living organism is perturbed. However, the concept of homeostasis not only encompasses reactive homeostasis (RH) but should also be extended to include predictive homeostasis $(\mathrm{PH})$ mechanisms, operating recursively and in coordination with one another in the face of environmental or external challenges (Yanine and Rother, 2017; Yanine and Sahoo, 2017). While in another context altogether, homeostaticity has been defined as a property of databases wherein the database has the ability "to restore its integrity constraints after ruinous disturbances of its medium" (Cannon, 1929; Dekhtyar and Dikovsky, 1996); in the context of energy sustainability, 
homeostaticity is defined as a property of sustainable energy systems (SES) whereby the energy system has the ability to respond to challenges and perturbations very rapidly and effectively (in fractions of a second), so as to restore systems operation's stability and continuity while, at the same time, striving to attain optimal equilibrium between the amount of electricity supplied by the energy system and the demand for electrical energy from the loads. The essential point here is not only to preserve systems stability and continuity of operations in electric power systems but to reach and maintain optimal equilibrium of the energy system. Reactive homeostasis - as the name suggests - is a feedback-enabled mechanism that alerts and prompts the system to act when there is an imbalance between supply and demand in order to attain homeostaticity (Yanine and Rother, 2017; Yanine and Sahoo, 2017). The proposed application of energy homeostaticity for the microgrid is shown in Figure 1.

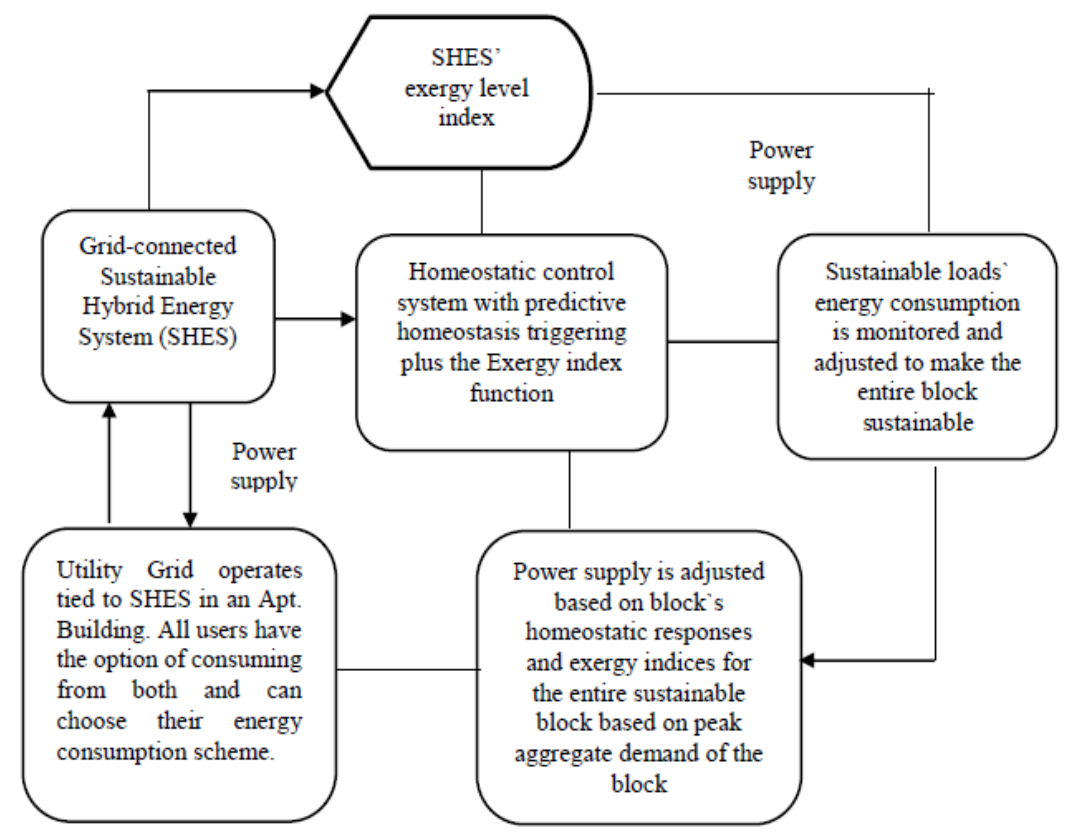

Figure 1: Diagram showing predictive and reactive homeostasis mechanisms operating as part of the HC of the microgrid, this time with energy storage (Cordova and Yanine, 2012; Oceanic and Service, 2013). Source: own elaboration

\section{Control engineering design}

This section details the control strategy designed to efficiently manage the available energy of both the microgrid and the network (utility grid) as well as their dynamic interaction, reducing consumers' electricity costs as well as helping the utility to manage a more orderly and predictable hourly load. This is done by better assigning its energy supplying resources under any given circumstance, with the incorporation of localized sustainable hybrid energy systems (SHES) in the form of grid-tied microgrids of their own devise and operation, and providing incentives to change towards a more efficient and sustainable energy consumption. It is important to realize that the utility's customers can benefit from special pricing mechanisms given the time-of-use (TOU) of electricity so that pricing serves as an efficient and cost-effective way of adequately managing electricity demand response during different hourly tariffs under normal conditions, which aims at relieving peak electricity demand from the electric utility (Uckun, 2012). In this regard the customers' participation is crucial for the success of such pricing mechanisms (Uckun, 2012). In order to fulfill the potential of such programs, customers must be able to access electricity tariffs and understand their terms (Uckun, 2012). Thus strategies for integrating renewable generation employing SHES are important not only because of peak load shifting, but also because of the need to tap into localized onsite solar photovoltaic generation along with solar thermal energy for heating and $\mathrm{AC}$, providing the utility grid the support and backup it needs.

Under this operation scheme, there is no such thing as energy independence from the grid, unless of course, there is no grid available as it occurs in remote and isolated communities and tiny villages located outside of 
the utility's electricity distribution range. Rather SHES and the utility grid must complement and support each other and both should rightly be operated by the electric utility itself, given the technical expertise, support and electric power distribution's industry infrastructure and ownership. Some authors have advanced the idea of electric power distribution decentralization by means of electric utilities installing localized electrical hubs as an effective way to integrate renewable energy resources and to provide additional services with little or no impact to the utility grid's operation (Wearing and McDonald, 2010; Rearte-Jorquera and Barrueto-Guzmán, 2015).

The homeostatic control strategy based on energy homeostaticity, unlike other control systems, considers the role that the energy users (residential and commercial electricity consumers) can play as "active loads", conscientiously responding to the network needs and to the possibilities of the microgrid's supply, both of which seek to motivate and entice consumers by economic incentives as well as social and technical ones. Moreover, energy storage plays a key role in the model as it enhances and strengthens thriftiness in energy consumption. This type of energy system is able to self-regulate and adapt itself when integrating and interacting with other higher level complex systems (meta system) like the utility grid, where the customers' load profile and current demand is included. The supervisory control strategy considered here is inspired in homeostasis of living organisms, which consists on the ability of living beings to keep certain variables in a steady, self-regulated, dynamic equilibrium state or within certain predefined limits to guarantee such equilibrium (Cordova and Yanine, 2012). For this the SHES must be adaptive and be capable of changing some parameters of their internal structure whenever is necessary to maintain energy homeostaticity. The structure of the simulated network can be seen in Figure 2. Its characteristics are detailed in Table 1.

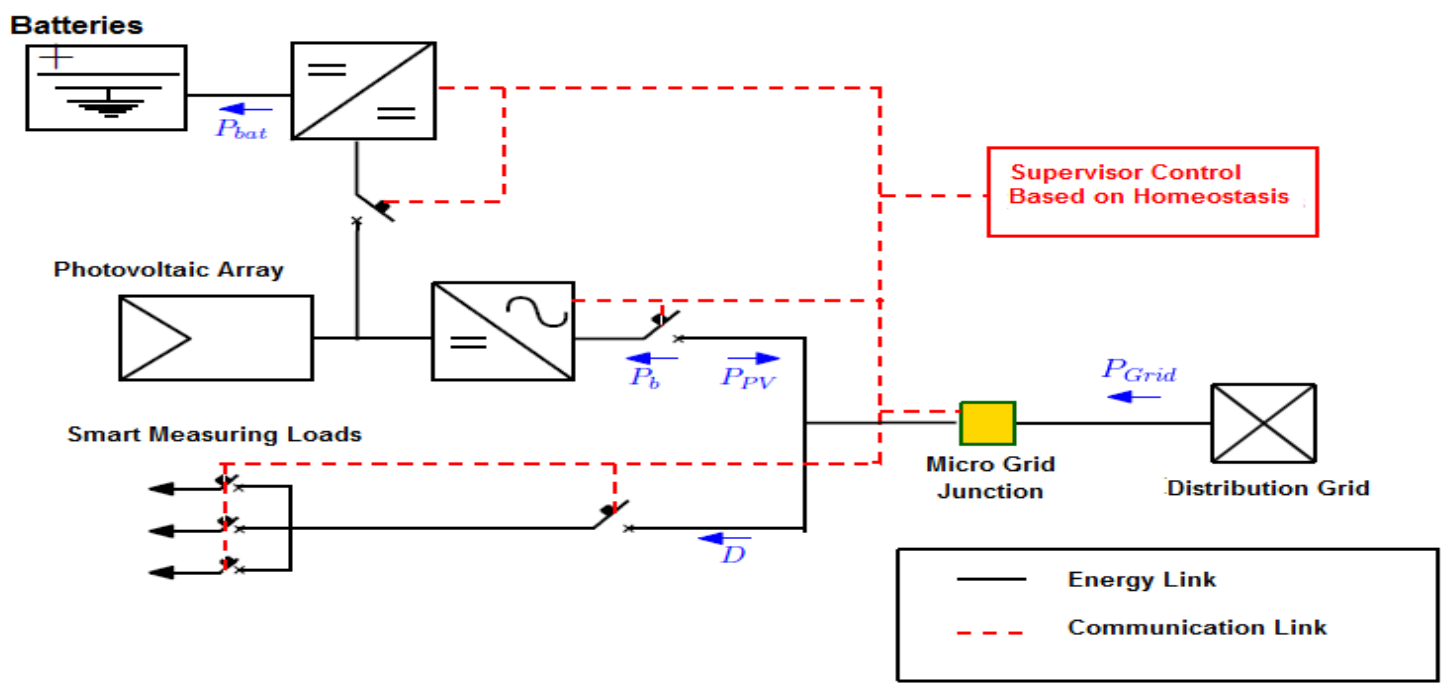

Figure 2: Global SHES diagram scheme to be operated by ENEL Distribucion for the new electricity pricing program strategy to incorporate renewables to the grid's supply taking into account the efficiency of the battery charging/ discharging process. Source: own elaboration.

Table 1: Components comprising the grid-tied microgrid mounted on a residential building

\begin{tabular}{|c|c|}
\hline Component & Size \\
\hline PV Plant & $40 \mathrm{kWp}$ \\
\hline Inverter DC/AC & $40 \mathrm{~kW}$ \\
\hline Battery bank & $0-50-100-150 \mathrm{kWh}$ \\
\hline
\end{tabular}

The simulation of 50, 100 and $150 \mathrm{kWh}$ batteries on the grid-tied microgrid installed in the residential building has been performed. The results obtained regarding change of energy cost in every case are presented next. 


\section{1. $50 \mathrm{kWh}$ battery}

It is very important here to note the paramount role that energy storage plays in the operation of the energy homeostaticity model. The first case to consider is the battery with capacity of $50 \mathrm{kWh}$. The electricity tariff (or electric rate) being charged for each of the apartments of the 12 stories residential building can vary according to the protocol they choose. In the graph of Figure 4 you can see what happens when you take the BT1 protocol (in black), AT43 without battery (in blue) and AT43 with $50 \mathrm{kWh}$ battery (in red). It should be noted that the left axis is in US\$ per $\mathrm{kWh}$. Each electric rate varies with time of day and gets more expensive as the day moves to peak hours which are between 6 PM and 11 PM.

Figure 5 shows the power flow with a $50 \mathrm{kWh}$ battery in operation: in red the aggregate demand, in blue the power from the electrical distribution network, in green the photovoltaic power, in yellow the power of the battery, in pink the power absorbed by the network and in black the power limit.

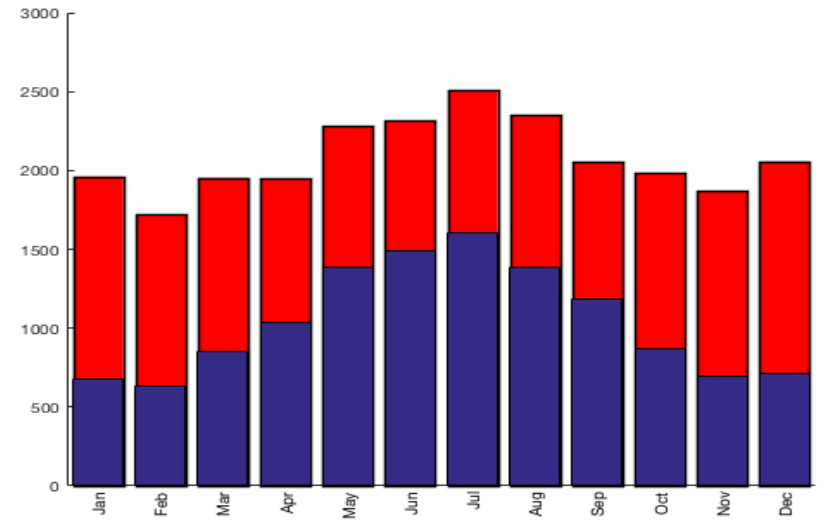

Figure 3: Electricity cost in US Dollars with battery of $50 \mathrm{kWh}$

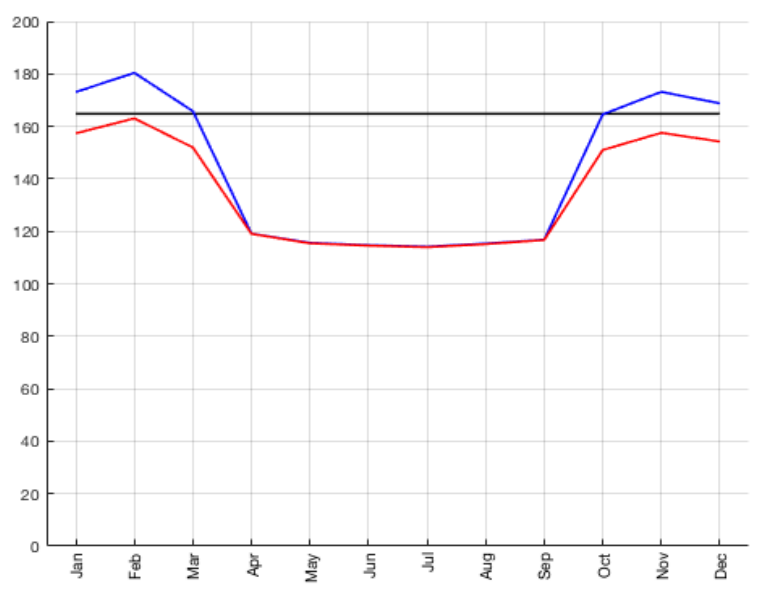

Figure 4: Electric rate in US Dollars with battery of $50 \mathrm{kWh}$

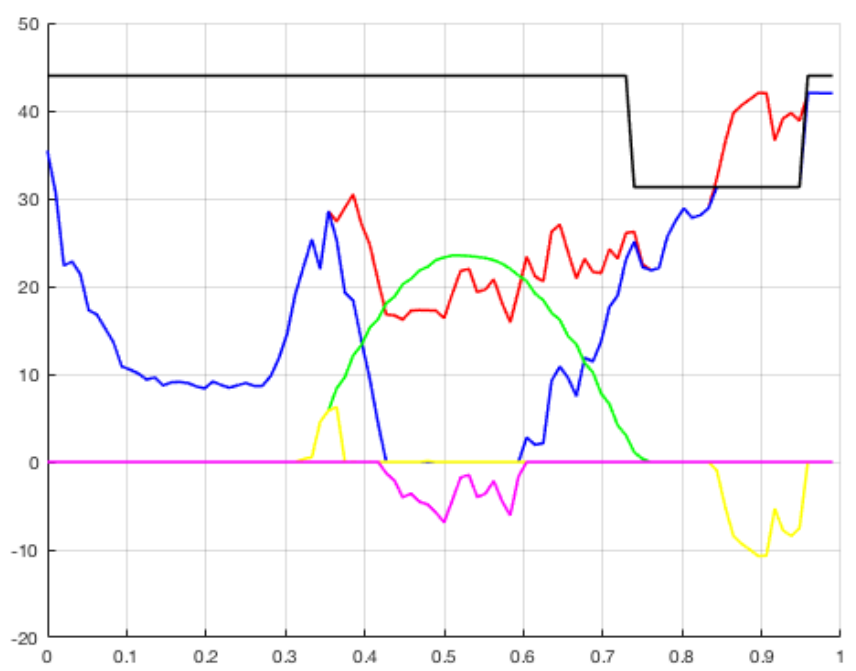

Figure 5: Power flow with a $50 \mathrm{kWh}$ battery in operation

For the simulation of the system proposed in the example shown as an illustration of the system's model, 3 types of batteries were chosen and tested by the homeostatic control system's simulation for the grid-tied microgrid installed in a residential building in Las Condes, Santiago de Chile. Each one of the 3 types alters the graphs as you can see below. In the following graph you can see the difference in annual costs of clients who do not control their electricity consumption by means of the energy homeostaticity model in use (in red) 
and those that do use it with a $50 \mathrm{Kwh}$ battery as energy storage. The electricity rate applied by the electric utility is the AT- 43 .

\section{2. $100 \mathrm{kWh}$ battery}

As in the case of the $50 \mathrm{kWh}$ battery, the difference in annual costs (Figure 6) can be seen for customers who opt for not having their electricity consumption being controlled by the homeostatic control system of the microgrid with their energy use (in red) and those who do use the system this time with a $100 \mathrm{kWh}$. The electric rate applied is AT-43.

Figure 7 shows the power flow with a $100 \mathrm{kWh}$ battery in operation: in red the aggregate demand, in blue the power from the distribution network, in green the photovoltaic power from the grid-tied microgrid, in yellow the power of the battery, and in pink the power absorbed by the network and black the power limit set. Here the simulation shows how increasing the size of the battery by doubling the energy storage capacity has an effect that typifies perfectly well what the model seeks to instill in the energy consumers: the more energy the system can save the higher the benefits for all of the parties involved and the more sustainable and resilient the energy system becomes, especially when considering the role of the utility's electricity distribution network which is acting as the meta system of the sustainable block (Yanine and Rother, 2017; Yanine and Sahoo, 2017).

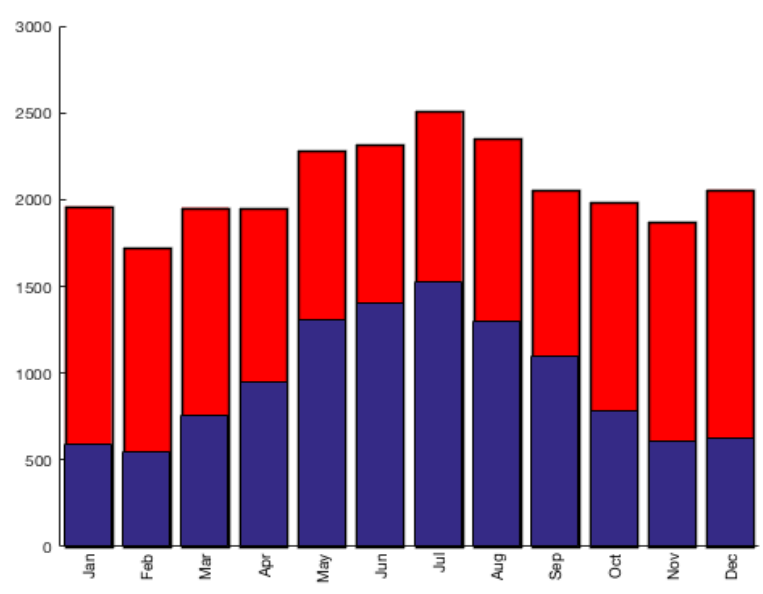

Figure 6: Cost in US Dollars battery of $100 \mathrm{kWh}$

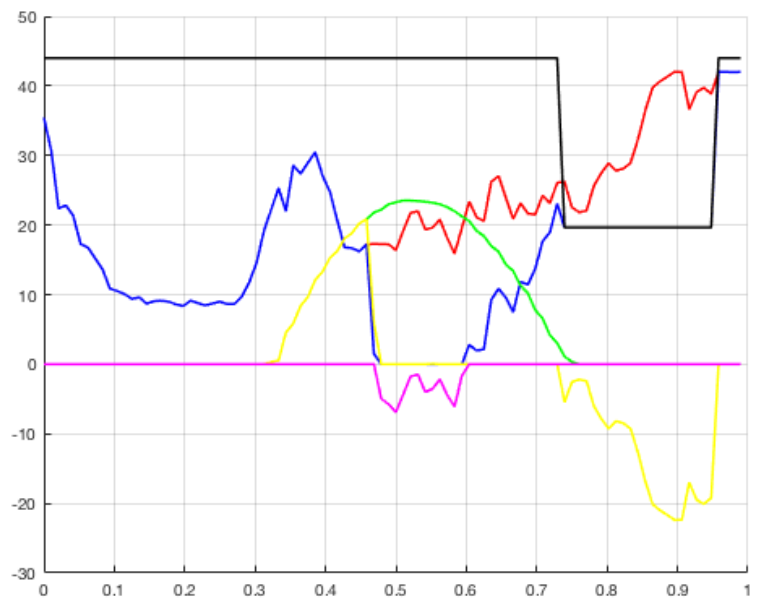

Figure 7: Power flow with a $100 \mathrm{kWh}$ battery

\section{3. $150 \mathrm{kWh}$ battery}

The rate used is AT-43 for the chart showing the cost in US dollars of residential customers that use the homeostatic control system, this time with a $150 \mathrm{kWh}$ battery in place, against those who do not control their energy use and choose to draw their electric supply directly and entirely from the distribution network, without the input of the microgrid's supply. 


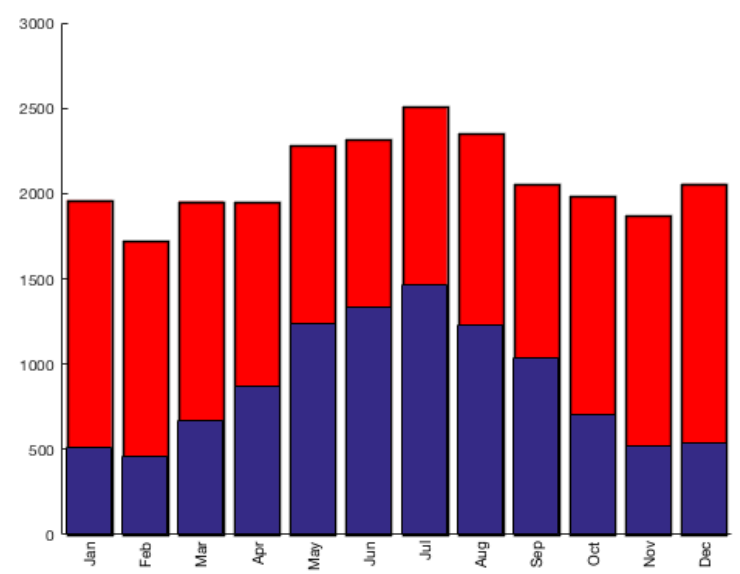

Figure 8: Cost in US Dollars with battery of $150 \mathrm{kWh}$

\subsection{Discussion}

In order to guarantee the fulfillment of the control objectives, the storage unit is designed to perform not only peak shaving and energy backup service but also to act as an energy homeostaticity enhancer and also an exergy booster. Peak shaving is widely known technique to flatten the customer electric demand curve. This technique is convenient in cases where energy price varies sharply depending on the day time, i.e. where electricity consumed or power demanded in hours of low demand (off-peak) is considerably cheaper than in hours of high demand (peak). Energy storage or backup is desired when the local distribution grid is not in operation due to a fault or cannot provide the necessary energy quality. In this operation condition, the storage unit provides reliability, availability and the required power quality. Considering the above mentioned requirements and characteristics, the introduction of an energy storage unit is a main issue for ENEL Distribution. Also important while designing a microgrid, are variables such as energy efficiency, duration, power density and energy density all of which are essential parameters to consider, since they affect the overall storage cost.

In Table 2 below there are some technical characteristics of the two technologies. As it is observed, Lithium battery density is much higher than the battery of Acid- $\mathrm{Pb}$, it also has a voltage per cell of $3.7 \mathrm{~V}$, which decreases the number of cells in series to reach a certain voltage. In this work, the technical characteristics provided by the commercial Tesla Powerwall battery (https://www.tesla.com/powerwall) will be adopted for simulation.

TABLE 2: COMPARISON TABLE BETWEEN BATTERIES

\begin{tabular}{l|c|c}
\cline { 2 - 3 } & Lead Acid & Lithium-ion \\
\hline \hline Energy Density $(\mathrm{Wh} / \mathrm{L})$ & 100 & 250 \\
Specific Energy $(\mathrm{Wh} / \mathrm{kg})$ & 40 & 150 \\
Initial Cost $(\$ / \mathrm{kWh})$ & 120 & 600 \\
Cycle life & 1200 @ 50\% DOD & $1900 @ 80 \% \mathrm{DOD}$ \\
Typical SOC window & $50 \%$ & $80 \%$ \\
Duration & 20 years & 20 years \\
Voltage increment & 2 & $3.7 \mathrm{~V}$ \\
\hline
\end{tabular}

\subsection{Conclusions}

The results of the simulations show that the addition of energy storage capacity and its management through the energy homeostaticity model proposed here for a residential building in Santiago, Chile has a high impact in the energy cost, as well as in residents' awareness of the importance of using green energy and exercising thriftiness and efficiency in electricity usage. Hence their advantages are evident. Moreover, the benefit not only stems from these facts but also it can be seen that energy storage also potentiates energy homeostaticity in grid-tied microgrids. Given the very nature of energy systems in general, particularly when renewable energy is involved, their synergistic divergence is expected, particularly in very diverse residential as well as 
commercial communities of energy users, such as those found in any big urban area. This is becaue the diversity as well as the intensity of electricity usage, particularly when power consumption is significant, creates and incentive for energy users to collaborate and to share the benefits of green energy. This ongoing systemic evolution subsequently provides an additional adaptive capacity of the metasystem in the face of harsh perturnations such as sysmic activity, string winds, dump rain and other phenomena that can interrupt or diminish the electric power distribution grid's ability to supply electricity normally. The relationship among energy users and also the relationship between them the electric utility company with the grid-tied microgrid is vital and must be reinforce with the right incentives. All of these players, the community of users, the electric utility and the grid-tied microgrid together comprise what has been termed a sustainable block in the literature (Yanine, et al. 2018)

\section{Acknowledgements}

Dr. Fernando Yanine is grateful to CONICYT of Chile for his scholarship endowment of his Postdoctoral FONDECYT No 3170399 "BUILDING SUSTAINABLE ENERGY SYSTEMS TIED TO GRID: A RESEARCH PROJECT PARTNERSHIP WITH CHILECTRA TO INSTALL HOMEOSTATICALLY CONTROLLED MICROGRIDS IN APARTMENT BUILDINGS" and to ENEL Distribucion for its auspice and support. Special thanks are also given to Universidad Finis Terrae for its ongoing support for this research initiative and to the Dept. of Electrical Engineering of UTFSM.

Dr. Antonio Sanchez-Squella is supported by a research grant from FONDECYT \#11150911 of Chile.

D. Antonio Parejo is supported by the research grant "Formacion de Profesorado Universitario" by the Ministry of Education, Culture and Sport (Government of Spain).

\section{References}

[1] A. Becena, M. Diaz, J.C. Zagal, 2012. "Feasibility study of using a small satellite constellation to forecast, monitor and mitigate natural and man-made disasters in Chile and similar developing countries"; Small Satellite Conference, ALL2012; 36. 2012

[2] E. S. Blake, T. B. Kimberlain, R. J. Berg., J. P. Cangialosi \& J. L. Beven II, "National hurricane center". Tropical Cyclone Report, Hurricane Sandy. 2013

[3] W.B Cannon, "Organization for physiological homeostasis". Physiological reviews 9(3), 399-431. 1929.

[3] A. Becena, M. Diaz, J.C. Zagal, 2012. "Feasibility study of using a small satellite constellation to forecast, monitor and mitigate natural and man-made disasters in Chile and similar developing countries"; Small Satellite Conference, ALL2012; 36. 2012

[4] E. S. Blake, T. B. Kimberlain, R. J. Berg., J. P. Cangialosi \& J. L. Beven II, "National hurricane center". Tropical Cyclone Report, Hurricane Sandy. 2013

[5] W.B Cannon, "Organization for physiological homeostasis". Physiological reviews 9(3), 399-431. 1929.

[6] W.B. Cannon. "Stress and strains of homeostasis". American Journal of Medical Science 189, 1-14. 1935

[7] F.M. Cordova, F.F Yanine, "Homeostatic control of sustainable energy grid applied to natural disasters". International Journal of Computers Communications \& Control 8(1), 50-60. 2012.

[8] M.I. Dekhtyar, A.J., Dikovsky, "On homeostatic behavior of dynamic deductive data bases", in: Springer (Ed.), International Andrei Ershov Memorial Conference Perspectives System Informatics. Heidelberg, Berlin, pp. 420-432. 1996.

[9] Oceanic, U.S.N., Service, A.A.N.W. "Hurricane/Post-Tropical Cyclone Sandy, October 22-29, 2012" (PDF) (Service Assessment). May 2013, p. 10. Archived from the original on June 2, 2013. (retrieved December 29, 2018).

[10] H. A. Rearte-Jorquera, A. Sánchez-Squella, H. Pulgar-Painemal, A. Barrueto-Guzmán, "Impact of Residential Photovoltaic Generation in Smart Grid Operation: Real Example". Procedia Computer Science 55, 1390-1399. 2015.

[11] C. Uckun, "Dynamic electricity pricing for smart homes". The University of Chicago. 2012.

S. L. Wearing, M. Wearing, \& M. McDonald; "Understanding local power and interactional processes in sustainable tourism: Exploring village-tour operator relations on the Kokoda Track, Papua New Guinea". Journal of Sustainable Tourism, 18(1), 61-76. 2010 
[12] F. F. Yanine, A. Sanchez-Squella, A. Barrueto, F. M. Cordova, S. K Sahoo; "Engineering Sustainable Energy Systems: How Reactive and Predictive Homeostatic Control Can Prepare Electric Power Systems for Environmental Challenges". Procedia Computer Science 439-446. 2017

[13] F. Yanine, A. Sanchez-Squella A. Barrueto A. Tosso F. M. Cordova, H. C. Rother, "Reviewing homeostasis of sustainable energy systems: How reactive and predictive homeostasis can enable electric utilities to operate distributed generation as part of their power supply services". Renewable and Sustainable Energy Reviews, 81, 2879-2892. 2018

Web sites:

Web-1: https://microgridknowledge.com/hybrid-microgrids, consulted 31 March 2018.

Web-2: http://www.iea.org/Textbase/npsum/US2014sum.pdf, consulted 31 March 2018. 